\title{
Correlates of Pro-Environmental Behavior at Railway Station
}

\author{
Deva Pramod.V.B \\ M.Sc. Applied Psychology, Department of Psychology, Bharathiar University, India
}

\begin{abstract}
Indian Railway Stations are criticised for its cleanliness. Throwing the food wastes to the railway track is a common event at Railway stations. So the current study is tend to explore the power of variables proposed by Theory of Planned Behavior (TPB) to predict the Pro-environmental Behavior at the Railway Station. The sample consists of 60 individuals from Calicut and Shoranur Railway Stations in Kerala, using Convenient Sampling method. The Scale to measure Pro-environmental Behavioral Intention, Perceived Behavioral Control (PBC), Subjective norms and Attitude towards Pro environmental behavior are developed specifically for the current research. Results of Correlation and ' $t$ ' test indicate that all the expected variables are significantly related to Pro-environmental Behavior Intention. Variation in Pro-environmental Behavioral Intention with respect to Sex and Geographical location are found to be insignificant.
\end{abstract}

Keywords: Pro-environmental Behavioral Intention, Perceived Behavioral Control, Subjective Norms, Attitude towards Pro-environmental Behavior

\section{Introduction}

Many of today's environmental problems are, at least to some extent, direct or indirect consequences of people's everyday behaviors. Travel, consumption, waste disposal, and the use of energy in the household are all environmentally significant behaviors that need to be changed in an environmentally friendly direction. Although many people view themselves as "environmentalists" (Pieters, Bijmolt, van Raaij \& de Kruijk, 1998), they do not translate their attitudes into pro environmental behavior. One reason may be that the choice between acting in a pro environmental way and not doing so often involves a conflict between immediate individual and long-term collective interests. The individual benefits obtained from traveling by car, buying food and other products without consideration of negative environmental impacts, not recycling, and having improper management of wastes, whereas the negative environmental effects of such behaviors are often uncertain consequences in the future.

Each person has his/her reasons why they behave the way they do. Individual's behavior to the environment is influenced by a wide range of influences (factors). If we ask "what are the factors which most influence the overall human behavior to the environment?", we can say: there is no easy answer to such question. Instead of searching the answer, let us try to understand these factors.

Here a sustainable behavior pattern is needed and it's very relevant. And can be called as Proenvironmental behavior. It can be defined as the action of an individual or group that advocates the sustainable or diminished use of natural resources (Sivek \& Hungerford, 1989/90). As it is difficult to measure actual behavior, it is proposed that it is the expressed intent of an individual to perform a pro-environment behavior that provides a more accurate assessment of their future actions. The following terms can be used as equivalents for pro environmental behavior "environmentally responsible behavior" (Kaiser et al., 1999), "ecological behavior" (Axelrod, Lehman 1993, Kaiser et al., 1999) and "sustainable behavior" (Clayton \& Myers, 2009).

\section{Theory of Reasoned Action and the Theory of Planned Behavior}

The Theory of Reasoned Action (TRA) and the Theory of Planned Behavior (TPB) focus on theoretical constructs concerned with individual motivational factors as determinants of the likelihood of performing a specific behavior. TRA and TPB both assume the best predictor of a behavior is behavioral intention, which in turn is determined by attitude toward the behavior and social normative perceptions regarding it. TPB is an extension of the TRA and includes an additional construct: perceived control over performance of the behavior. In recent years, Fishbein and colleagues have further expanded TRA and TPB to include components from other major behavioral theories and have proposed use of an Integrated Behavioral Model (IBM).

The TRA and TPB, which focus on the constructs of attitude, subjective norm, and perceived control, explain a large proportion of the variance in behavioral intention and predict a number of different behaviors, including health behaviors. Evidence comes from hundreds of studies that have been summarized in several meta-analyses and reviews (Armitage \& Conner, 2001; Albarracin, Johnson, Fishbein, \& Muellerleile, 2001; Albarracin et al., 2003; Albarracin, Kumkale, \& Johnson, 2004; Albarracin et al., 2005; Downs \& Hausenblas, 2005; Durantini et al., 2006; Hardeman et al., 2002; Sheeran \& Taylor, 1999; Webb \& Sheeran, 2006). 
Although TRA and TPB have been criticized, based on whether correlational results can explain behavior (Weinstein, 2007), many published intervention study reports show that changing TRA or TPB constructs leads to subsequent change in behaviors (Albarracin and others, 2003, 2005; Jemmott, Jemmott, and Fong, 1992; Kamb and others, 1998; Rhodes and others, 2007). TRA and TPB have been used successfully to predict and explain a wide range of health behaviors and intentions.

TRA asserts that the most important determinant of behavior is behavioral intention. Direct determinants of individuals' behavioral intention are their attitude toward performing the behavior and their subjective norm associated with the behavior. TPB adds perceived control over the behavior, taking into account situations where one may not have complete volitional control over a behavior.

Attitude is determined by the individual's beliefs about outcomes or attributes of performing the behavior (behavioral beliefs), weighted by evaluations of those outcomes or attributes. Thus, a person who holds strong beliefs that positively valued outcomes will result from performing the behavior will have a positive attitude toward the behavior. Conversely, a person who holds strong beliefs that negatively valued outcomes will result from the behavior will have a negative attitude.

Similarly, a person's subjective norm is determined by his or her normative beliefs, that is, whether important referent individuals approve or disapprove of performing the behavior, weighted by his or her motivation to comply with those referents. A person who believes that certain referents think she should perform a behavior and is motivated to meet expectations of those referents will hold a positive subjective norm. Conversely, a person who believes these referents think she should not perform the behavior will have a negative subjective norm, and a person who is less motivated to comply with those referents will have a relatively neutral subjective norm.

TRA assumes that the most important direct determinant of behavior is behavioral intention. Success of the theory in explaining behavior depends on the degree to which the behavior is under volitional control (that is, individuals can exercise a large degree of control over the behavior). It is not clear that the TRA components are sufficient to predict behaviors in which volitional control is reduced. Thus, Ajzen and colleagues (Ajzen, 1991; Ajzen and Driver, 1991; Ajzen and Madden, 1986) added Perceived Behavioral Control to TRA to account for factors outside individual control that may affect intentions and behaviors. With this addition, they created the Theory of Planned Behavior. Perceived control is determined by control beliefs concerning the presence or absence of facilitators and barriers to behavioral performance, weighted by their perceived power or the impact of each control factor to facilitate or inhibit the behavior.

Ajzen's inclusion of perceived control (Ajzen, 1991) was based in part on the idea that behavioral performance is determined jointly by motivation (intention) and ability (behavioral control). A person's perception of control over behavioral performance, together with intention, is expected to have a direct effect on behavior, particularly when perceived control is an accurate assessment of actual control over the behavior and when volitional control is not high. The effect of perceived control declines, and intention is a sufficient behavioral predictor in situations in which volitional control over the behavior is high (Madden, Ellen, and Ajzen, 1992). Thus, similar to Triandis's (1980) conceptualization of facilitating conditions, perceived control is expected to moderate the effect of intention on behavior. However, this interaction hypothesis has received very little empirical support (Ajzen, 1991; Yzer, 2007).

TPB also postulates that perceived control is an independent determinant of behavioral intention, along with attitude toward the behavior and subjective norm. Holding attitude and subjective norm constant, a person's perception of the ease or difficulty of behavioral performance will affect his behavioral intention. Relative weights of these three factors in determining intentions should vary for different behaviors and populations. Few studies have operationalized perceived control using the underlying measures of control beliefs and perceived power; instead, researchers have mostly used the direct measure of perceived control (Ajzen, 2002).

TRA and TPB assume a causal chain that links behavioral beliefs, normative beliefs, and control beliefs to behavioral intentions and behaviors via attitudes, subjective norms, and perceived control. Hypothesized causal relationships among model components are clearly specified, and measurement and computation are delineated by Ajzen and Fishbein (Ajzen and Fishbein, 1980; Ajzen, 1991). This is one of the major strengths of the TRA/TPB approach. Other factors, including demographic and environmental characteristics, are assumed to operate through model constructs and do not independently contribute to explain the likelihood of performing a behavior.

\section{An Integrated Behavioral Model}

As in TRA/TPB, the most important determinant of behavior in the IBM is intention to perform the behavior. Without motivation, a person is unlikely to carry out a recommended behavior. Four other components directly affect behavior (Jaccard, Dodge, and Dittus, 2002). Three of these are important in determining whether behavioral intentions can result in behavioral performance. First, even if a person has a 
strong behavioral intention, she needs knowledge and skill to carry out the behavior. Second, there should be no or few environmental constraints that make behavioral performance very difficult or impossible (Triandis, 1980). Third, behavior should be salient to the person (Becker, 1974). Finally, experience performing the behavior may make it habitual, so that intention becomes less important in determining behavioral performance for that individual (Triandis, 1980).

Thus, a particular behavior is most likely to occur if (1) a person has a strong intention to perform it and the knowledge and skill to do so, (2) there is no serious environmental constraint preventing performance, (3) the behavior is salient, and (4) the person has performed the behavior previously. Clearly, strong behavioral intentions are required for an intervention addressing model components, such as skills or environmental constraints, to affect behavioral performance. According to the model, behavioral intention is determined by three construct categories. The first is attitude toward the behavior, defined as a person's overall favorableness or unfavorableness toward performing the behavior. Many theorists have described attitude as composed of affective and cognitive dimensions (Triandis, 1980; Fishbein, 2007; French and others, 2005). Experiential attitude or affect (Fishbein, 2007) is the individual's emotional response to the idea of performing a recommended behavior. Individuals with a strong negative emotional response to the behavior are unlikely to perform it, whereas those with a strong positive emotional reaction are more likely to engage in it. Instrumental attitude is cognitively based, determined by beliefs about outcomes of behavioral performance, as in the TRA/TPB. Conceptualization of experiential attitude (affect) is different from "mood or arousal," which Fishbein (2007) argues may affect intention indirectly by influencing perceptions of behavioral outcome likelihood or evaluation of outcomes.

Second, perceived norm reflects the social pressure one feels to perform or not perform a particular behavior. Fishbein (2007) indicates that subjective norm, as defined in TRA/TPB as an injunctive norm (normative beliefs about what others think one should do and motivation to comply), may not fully capture normative influence. In addition, perceptions about what others in one's social or personal networks are doing (descriptive norm) may also be an important part of normative influence. This construct captures the strong social identity in certain cultures which, according to some theorists, is an indicator of normative influence (Bagozzi and Lee, 2002; Triandis, 1980; Triandis and others, 1988).

Finally, personal agency, described by Bandura (2006) as bringing one's influence to bear on one's own functioning and environmental events. In IBM, personal agency consists of two constructs - self-efficacy and perceived control. Perceived control, as described previously, is one's perceived amount of control over behavioral performance, determined by one's perception of the degree to which various environmental factors make it easy versus difficult to carry out the behavior. In contrast, self-efficacy is one's degree of confidence in the ability to perform the behavior in the face of various obstacles or challenges. This is measured by having respondents rate their behavioral confidence on bipolar "certain I could not-certain I could" scales. Although only a few studies have discussed the similarities and differences between these two constructs (Ajzen, 2002; Fishbein, 2007), our studies suggest the utility of including both measures.

The relative importance of the three categories of theoretical constructs (attitude, perceived norm, personal agency) in determining behavioral intention may vary for different behaviors and for different populations. For example, intention to perform one behavior may be primarily determined by attitude toward the behavior, while another behavioral intention may be determined largely by normative influence.

Similarly, intention to perform a particular behavior may be primarily under attitudinal influence in one population, while more influenced by normative influence or personal agency in another population. Thus, to design effective interventions to influence behavioral intentions, it is important first to determine the degree to which that intention is influenced by attitude (experiential and instrumental), perceived norm (injunctive and descriptive), and personal agency (self-efficacy and perceived control). Once this is understood for a particular behavior and population, an understanding of the determinants of those constructs also is essential.

Instrumental and experiential attitudes, injunctive and descriptive norms, self-efficacy, and perceived control are all functions of underlying beliefs. In contrast to TRA and TPB, evaluation of outcomes is not specified in this model. Research suggests that, for many health behaviors, there is very little variance in people's evaluations of behavioral outcomes (von Haeften, Fishbein, Kasprzyk, and Montaño, 2001; von Haeften and Kenski, 2001; Fishbein, von Haeften, and Appleyard, 2001). If most people agree in their evaluations of the various behavioral outcomes, there is little benefit in measuring outcome evaluations. However, if preliminary study of a behavior indicates individual variation in outcome evaluations, this measure should be assessed.

Perceived norms are a function of normative beliefs, as in the TRA and TPB. The stronger one's beliefs that specific individuals or groups think one should perform the behavior or that others are performing the behavior, the stronger one's perception of social pressure to carry out the behavior. Again, in contrast to TRA/TPB, motivation to comply with individuals or groups is not specified in the IBM because, as with outcome evaluations, we have found that there is often little variance in these measures. However, if variance is 
found in motivation to comply, this should also be measured. Perceived control, as described earlier in the TPB, is a function of control beliefs about the likelihood of occurrence of various facilitating or constraining conditions, weighted by the perceived effect of those conditions in making behavioral performance easy or difficult. Finally, the stronger one's beliefs that one can perform the behavior despite various specific barriers, the greater one's self-efficacy about carrying out the behavior.

Most important in the application of the IBM as a framework to identify specific belief targets for behavior change interventions is the conceptualization of experiential and instrumental attitudes, injunctive and descriptive norms, and perceived control and self-efficacy being determined by specific underlying beliefs. This is described in detail in the application that follows. Interventions built on one model construct may have effects that further affect the same or other model constructs. For example, by changing normative beliefs, one may be sufficiently motivated to engage in the behavior once. If this is a positive experience, it may result in more positive behavioral beliefs, as well as positive emotional feelings about the behavior, leading to stronger future intention with respect to the behavior.

\subsection{Need and Research Problem}

One of the major aims of the subject psychology is to predict behavior. Prediction is important because people get a partial control of the consequences or events. In such a situation predicting the pro environmental behavior of the person is relevant since human beings has been abusing the nature since his birth. Existence of predictive factors may help to develop action plans to cultivate such behavior among human beings so that nature would be protected for more years.

Major theories predicting such behavior are Theory of Planned Behavior, Theory of reasoned Action and Integrated Behavioral Model. The present study is aimed to study the relationship of simplest predictors of behavior such as Attitude towards the behavior, Perceived Behavioral Control and subjective norms with the pro environmental behavior at railway station.

Indian railways stations are criticized for its cleanliness. Throwing the food wastes to the railway track is a common event at railway stations. So the currents study is tend to explore the power of variables proposed by Theory of planned behavior to predict the pro environmental behavior at railway station.

i.e., the present study addresses the following research problem:

Whether, Attitude towards pro-environment behavior, Perceived Behavioral control, and Subjective Norms is related to the Pro-environmental Behavioral intention?

\subsection{Hypotheses}

H1: Attitude towards pro-environment behavior, Perceived Behavioral control, and Subjective Norms is significantly related to the Pro-environmental Behavioral intention.

H2: There will be significant change in Pro-environmental Behavioral intention with respect to the Sex and geographical location.

\section{II. review of literature}

Using Ajzen's theory of planned behavior (TOPB), Cheung, Chan and Wong (1999) examined wastepaper-recycling behavior among college students in Hong Kong. Two hundred and eighty-two college students completed a questionnaire designed to measure various constructs related to recycling behavior. The results reveal that TOPB significantly predicted both behavioral intention and subsequent wastepaper-recycling behavior self-reported a month later. Perceived difficulty predicted behavioral intention and moderated the intention-behavior link, whereas perceived control had no significant effect. These findings cast doubt on the one-dimensional conceptualization of perceived behavioral control. By controlling for the TOPB constructs, general environmental knowledge significantly predicted behavior. Past behavior had a sizeable effect on predicting subsequent behavior, suggesting that TOPB plus knowledge are insufficient to predict recycling.

An expanded version of the theory of planned behavior (TPB) was used to predict and explain public transportation use. A pre-post design was used to examine changes in university students' bus ridership after the implementation of a universal bus pass (U-pass) program. Bus ridership significantly increased after the U-pass was implemented and associated changes in attitudes and beliefs about transportation modes were found. In both phases, students' public transportation use was well predicted by the original TPB. However, 2 additional construct - a descriptive norm, and the interaction between intention and perceived behavioral controlsignificantly improved prediction in both phases of the study. These constructs might be useful additions to the original TPB, at least in this behavioral domain (Heath \& Gifford, 2002).

New mandatory household recycling targets present a serious challenge to UK Local Authorities (LAs). The key to achieving these targets is participation by households in waste management and recycling 
schemes. However, for these schemes to be successful, they must be based on a thorough understanding of householder attitudes to recycling, and their perceptions of the barriers to recycling. The Theory of Planned Behavior (TPB), which provides a theoretical framework for systematically identifying the determinants of recycling behavior, was used as the basis for a study of 191 participants in a local curbside recycling scheme. The findings suggest that pro-recycling attitudes are the major contributor to recycling behavior, and that these attitudes are influenced firstly, by having the appropriate opportunities, facilities and knowledge to recycle, and secondly by not being deterred by the issues of physically recycling (for example time, space and inconvenience). Previous recycling experience, and a concern for the community and the consequences of recycling are also significant predictors of recycling behavior (Tongleta, Phillipsb \& Readc, 2004)

Fielding, Donald, and Louis (2008) incorporated identity constructs into the theory of planned behavior (TPB) to investigate intentions to engage in environmental activism. First year students and participants of a students of sustainability conference $(\mathrm{n}=169)$ were administered a questionnaire survey that measured standard TPB constructs as well as environmental group membership and self-identity as an environmental activist. Consistent with predictions, environmental group membership and self-identity were positive predictors of intentions. Thus, greater involvement in environmental groups and a stronger sense of the self as an environmental activist were associated with stronger intentions to engage in environmental activism. There was also evidence that self-identity was a stronger predictor of intentions for participants with low rather than high environmental group membership. In accordance with the standard TPB model, participants with more positive attitudes toward and a greater sense of normative support for environmental activism also had greater intentions to engage in the behavior.

Kaiser and Gutscher (2003) explored whether the theory of planned behavior (TPB) must abandon the notion that Perceived Behavioral Control (PBC) has a direct influence on behavior. In a cross-sectional survey of 895 Swiss residents, our hypothesis was tested by means of structural equation models. Applied specifically, PBC turned out to be a significant direct predictor of one's performance. A general version of the TPB based on aggregated measures, however, revealed $\mathrm{PBC}^{\prime}$ s direct influence on behavior to be no significant and, presumably, a non-universally applicable and thus no generalizable part of the theory. Intention determined $51 \%$ to $52 \%$ of people's ecological behavior, which supports the claim of a strong attitude-behavior relation. Attitude, subjective norms, and PBC, the 3 TPB components, account for $81 \%$ of intention's variance.

Beedell and Rehman (2000) attempts to illustrate the use of a structured social psychology methodology, the Theory of Planned Behavior, in explaining how and more crucially why farmers manage the existing wildlife and landscape features on their holdings. The hedge management behavior of Bedfordshire farmers is studied to illustrate the theory and it was found that the more 'conservation minded' ones regarded the conservation benefits of hedge management more likely to be true and value them more highly than other farmers do. Such farmers also felt under greater social pressure to manage their hedges. This use of the Theory of Planned Behavior suggests that it can provide a useful insight into farmers' decision-making processes and their conservation behavior.

The theory of planned behavior (TPB; I. Ajzen, 1985) was applied to drivers' compliance with speed limits. Questionnaire data were collected for 598 drivers at 2 time points separated by 3 months. TPB variables, demographic information, and self-reported prior behavior were measured at Time 1, and self-reported subsequent behavior was measured at Time 2. In line with the TPB, attitude, subjective norm, and perceived control were positively associated with behavioral intention, and intention and perceived control were positively associated with subsequent behavior. TPB variables mediated the effects of age and gender on behavior. Prior behavior was found to moderate the perceived control-intention and perceived control-subsequent behavior relationships (Elliott, Armitage, \& Baughan, 2003).

Binge drinking (i.e. consuming half the recommended weekly consumption of alcohol in a single session) is a common activity among young people. Using the Theory of Planned Behavior as its theoretical framework, this paper reports a study exploring the motivational and attitudinal factors underlying binge drinking in a sample of undergraduate students. Questionnaires were completed by 136 undergraduates which focused on their drinking behavior and their beliefs about binge drinking. Binge drinking was found to be more prevalent among male respondents, and a number of significant differences in the beliefs of male and female respondents were found which supported this difference in drinking behavior. A regression analysis identified two key predictors of the frequency of binge drinking; these being positive control beliefs and perceived behavioral control. Frequent binge drinkers were more likely to recognize the influence of a range of factors which may serve to encourage binge drinking (e.g. celebrating an event) and less likely to believe that the decision to engage in binge drinking is under their control (Norman, Bennett \& Lewis, 1998).

Motivations to recycle have been extensively studied adopting an attitude approach and, in particular, the theory of planned behavior frame (TPB Ajzen, 1998, 1991). However, several authors have provided evidence suggesting that self-identity dimensions can be a useful addition to the TPB within the domain of repeated behaviors such as recycling. To compare the predictive power of a new model of "Self-Expressive 
Behavior" with the TPB, a study was conducted in which, besides the classic variables of the TPB model (such as attitudes, subjective norms and perceived control), similarity between personal identities and "identity of typical recyclers" was also taken into account. Two hundred and thirty Italian subjects were recruited to study behavioral intentions concerning household recycling in relation to the variables mentioned above, derived from TPB and from Identity theory. Data analysis, based on structural equation modelling, shows that personal identity contributes significantly and independently to the explanation of intentions to recycle (Mannetti, Pierro \& Livi, 2004).

\subsection{Sample}

\section{III. methodology}

The sample consists of 60 individuals from Calicut and Shoranur Railway Station in Kerala, India. Convenient sampling method has been adopted for determining sample for the study.

\subsection{Variables and Operational Definitions}

Pro environmental behavioral intention: It is an indication of an individual's readiness to behave in a proper way in the railway station.

Perceived behavioral control (PBC): Perceived Behavioral Control refers to people's perception of the ease or difficulty of performing the behavior of interest. i.e., His/Her own belief about skill to manipulate his own pro environmental behavior.

Subjective norms: It can be defined as an individual's perception about the particular behavior, which is influenced by the judgment of significant others. It's a capacity to engage in pro environmental behavior in the absence of others support.

Attitude towards Pro environmental behavior: Individual's favorableness towards actions which are beneficial for the environment.

\subsection{Research Instruments}

The scale to measure Pro-environmental behavioral intention, Perceived Behavioral Control, Subjective norms, and Attitude towards Pro environmental behavior are developed for the special need of the research. Subjects are allowed to respond to the scale in a five point response pattern.

Pro environmental behavioral intention scale is an single item scale which directly probe the willingness to behave Pro - environmentally. Perceived behavioral control, Subjective norms, and Attitude towards Pro environmental behavior are measured with three items each the reliability coefficients of the scale are ranges from .87 to .92 . the sample

Personal data sheet used to measure the demographic profile such as Age, gender, education, etc., of

\section{Research Design}

Correlational research design is used to carry out the research. Correlational research tests for statistical relationships between variables. The researcher begins with the idea that there might be a relationship between two variables. Researcher then measures both variables for each of a large number of cases and checks to see if they are in fact related. It probably also involves null hypothesis testing to see if the observed relationship is statistically significant.

\section{Statistical Analysis}

Descriptive statistics such as Mean and Standard deviation are used to compare the Pro-environmental behavior with respect to the Sex and location of the sample, and Independent sample ' $t$ ' test is used to test the significance of the difference among the scores.

Karl Pearson product moment correlations coefficient is used to analyses the relationship among Proenvironment behavior, Perceived Behavioral control, Subjective Norms and Pro-environmental Behavioral intention.

\section{IV. results and discussion}

The present study aims to find out the relationship among Pro Environmental Behavioral Intention, Subjective Norms, Perceived Behavioral Control and Attitude. Sample includes 60 Adults were taken using convenient sampling method.

Table 1

Correlation among Pro Environmental Behavioral Intention, Subjective Norms, Perceived Behavioral Control and Attitude 
Correlates of Pro-Environmental Behavior at Railway Station

\begin{tabular}{|c|c|c|c|}
\hline Variable & 1 & 2 & 3 \\
\hline \multicolumn{4}{|l|}{ Attitude (1) } \\
\hline Perceived Behavioral Control (2) & $.378^{* *}$ & & \\
\hline Subjective Norms (3) & $.415^{* *}$ & $.447^{* *}$ & \\
\hline Pro Environmental Behavioral Intention (4) & $.705^{* *}$ & $.329^{* *}$ & $.381^{* *}$ \\
\hline
\end{tabular}

Results of the analysis presented in the table 1 indicate that Pro Environmental behavior is significantly and positively related to Attitude towards such behavior, Perceived Behavioral Control and Subjective norms ( $\mathrm{r}$ $=.705, .329, .381, \mathrm{p}<.01)$.

Thus the Hypothesis H1: Attitude towards pro-environment behavior, Perceived Behavioral control, and Subjective Norms is significantly related to the Pro-environmental Behavioral intention is accepted.

When people show a favorable attitude towards pro environmental behavior, have belief on their own abilities to promote such behavior along with the guts to behavior against the usual improper behavior of the society, people really tend to behave favorably towards the nature.

Pro environmental behavior, the action of an individual or group that advocates the sustainable or diminished use of natural resources, can be influence due to several factors. From the result of analysis, Pro Environmental behavior is significantly and positively related to Attitude towards such behavior, Perceived Behavioral Control and Subjective norms. Positive or negative evaluation of self-performance of the particular behavior can be stated as attitude, which have vital role in every individual's behavior. Here in the dimension of pro environmental behavior, from the analyzed result, it is clear that attitude towards such behavior have significant value and positive relation in bringing out or in the accomplishment of pro environmental behavior in an individual.

Another crucial dimension which correlates pro environmental behavior is perceived Behavioral Control; control refers to people's perception of the ease or difficulty of performing the behavior of interest. From the result analyzed, Perceived Behavioral Control have significance and positive relation towards sustainable behavior, pro environmental behavior, which point out that Perceived Behavioral Control can act as a grounds for reveal pro environmental behavior.

Subjective norms, which refers to the perception about the particular behavior, which is influenced by the judgment of significant others, is a further chief building block or source for bring up the pro environmental behavior. From the analyzed results, subjective norms have significance and positive relation towards ecological behavior or pro environmental behavior, which resources that subjective norms can perform a motive towards pro environmental behavior.

Further analyzing the results, the results shows that pro environmental behavior is significantly and positively related to attitude towards such behavior, Perceived Behavioral Control and Subjective norms. And it is understandable or clear that, in order to enhance pro environmental behavior, the aspects, positive or negative evaluation of self-performance of the particular behavior (attitude), people's perception of the ease or difficulty of performing the behavior of interest (perceived behavioral control) and perception about the particular behavior, which is influenced by the judgment of significant others (Subjective norms) are to be effectively stimulated or encouraged.

Table 2

Descriptive statistics and ' $t$ ' test for the Pro Environmental Behavioral Intention with respect to the sex

\begin{tabular}{lcccc}
\hline Gender & N & Mean & SD & t \\
\hline Male & 47 & 4.09 & .952 & .777 \\
Female & 13 & 4.31 & .751 & \\
\hline
\end{tabular}

Male and female gender tend to have similar Pro-environmental behavior intention $(t=.77, p>.05$, table 2). In the case of pro environmental behavior, a sustainable behavior, which is positively related to pro environmental behavior intension i.e. the individual's readiness to perform a behavior, here the readiness to perform pro environmental behavior, have no difference among gender. Both males and females show parallel or comparable pro environmental intentions. That means demographic characteristics have minor or insignificant role in bringing out of pro environmental behavior than internal characteristics such as attitude, PCB and subjective norms. And from the result it is clear that the above discussed internal characteristics have no power or significant difference over gender. Hence gender is independent and shows similar environmental behavior intention. 
Table 3

Descriptive statistics and ' $t$ ' test for the Pro Environmental Behavioral Intention with respect to the Location

\begin{tabular}{llccc}
\hline Gender & $\mathbf{N}$ & Mean & SD & T \\
\hline Urban & 18 & 3.78 & 1.263 & \multirow{2}{*}{1.26} \\
Rural & 46 & 4.13 & .885 & \\
\hline
\end{tabular}

Results of the ' $t$ ' test presented in the table 3 indicate that both Rural and urban people has similar Proenvironmental behavior intention $(\mathrm{t}=1.26, \mathrm{p}>.05)$.

Thus the Hypothesis H2: There will be significant change in Pro-environmental Behavioral intention with respect to the Sex and geographical location is rejected.

Location, which is being an important dimension in shaping a behavior among individuals, have vital role in performing a behavior. According to the result, location that is urban, which refers residing which connected to a town or a city or rural, which refers residing which is connected to country side or villages have no difference in pro environmental behavior intention, which further generates or bring to being in pro environmental behavior. That is, both people dwell or reside in urban and rural settlements have similar Proenvironmental behavior intention. And from the result it is clear that the internal characteristics, such as attitude, PCB and subjective norms have no or power or significant difference over location of residence, rural/urban and hence it is obviously independent.

\section{V. summary and conclusion}

One of the major aims of the subject psychology is to predict behavior. Prediction is important because people get a partial control of the consequences or events. In such a situation predicting the pro environmental behavior of the person is relevant since human beings has been abusing the nature since his birth. Existence of predictive factors may help to develop action plans to cultivate such behavior among human beings so that nature would be protected for more years.

Major theories predicting such behavior are Theory of Planned Behavior, Theory of reasoned Action and Integrated Behavioral Model. The present study is aimed to study the relationship of simplest predictors of behavior such as Attitude towards the behavior, Perceived Behavioral Control and subjective norms with the pro environmental behavior at railway station.

Indian railways stations are criticized for its cleanliness. Throwing the food wastes to the railway track is a common event at railway stations. So the currents study is tend to explore the power of variables proposed by Theory of planned behavior to predict the pro environmental behavior at railway station.

i.e., the present study addresses the following research problem:

Whether, Attitude towards pro-environment behavior, Perceived Behavioral control, and Subjective Norms is related to the Pro-environmental Behavioral intention?

The sample consists of 60 individuals from Calicut and Shoranur Railway station. Convenient sampling method has been adopted for determining sample for the study. Convenience Sampling is a nonprobabilistic sampling technique where subjects are selected because of convenient accessibility and proximity to the researcher. Since the subject selected the sampling method on the basis of convenience and availability, the sampling method has to be considered as convenient sampling method.

H1: Attitude towards pro-environment behavior, Perceived Behavioral control, and Subjective Norms is significantly related to the Pro-environmental Behavioral intention.

H2: There will be significant change in Pro-environmental Behavioral intention with respect to the Sex and geographical location.

The scale to measure Pro-environmental behavioral intention, Perceived behavioral control, Subjective norms, and Attitude towards Pro environmental behavior are developed for the special need of the research. Subjects are allowed to respond to the scale in a five point response pattern.

Findings of the present study are as follows:

When people show a favorable attitude towards pro environmental behavior, have belief on their own abilities to promote such behavior along with the guts to behavior against the usual improper behavior of the society, people really tend to behave favorably towards the nature. Male and female gender tend to have similar Pro-environmental behavior intention and both Rural and urban people has similar Pro-environmental behavior intention. 


\section{References}

[1] Pieters, R., Bijmolt, T., van Raaij, F., \& de Kruijk, M. (1998). "Consumers' attributions of pro environmental behavior, motivation and ability to self and others." Journal of Public Policy and Marketing, 17, 215-225.

[2] Sivek, D. J., \& Hungerford, H. (1989/1990). "Predictors of responsible behavior in members of Wisconsin conservation organizations." The Journal of Environmental Education, 21(2), 35-40.

[3] Kaiser, F. G. (1999). "Responsibility as a predictor of ecological behavior.” Journal of Environmental Psychology, 19, 243-253.

[4] Axelrod, L.J., \& Lehman, D. R. (1993). "Responding to environmental concern: what factors guide individual action?" Journal of Environmental Psychology, 13, 149-159.

[5] Clayton, S., \& Myers, G.(2009). “Conservation Psychology: Understanding and Promoting Human Care for Nature." Oxford, UK: Blackwell.

[6] Armitage, C. J., \& Conner, M. (2001). "Efficacy of the Theory of Planned Behavior: A Meta-Analytic Review."British Journal of Social Psychology, 40(Pt 4), 471-499.

[7] Albarracin, D., Johnson, B. T., Fishbein, M., \& Muellerleile, P. A. (2001). "Theories of Reasoned Action and Planned Behavior as Models of Condom Use: A Meta-analysis.” Psychological Bulletin, 127(1), 142-161.

[8] Albarracin, D., \& others. (2003). "Persuasive Communications to Change Actions: An Analysis of Behavioral and Cognitive Impact in HIV Prevention.” Health Psychology, 22, 166-177.

[9] Albarracin, D., Kumkale, G. T., \& Johnson, B. T. (2004) . "Influences of Social Power and Normative Support on Condom Use Decision: A Research Synthesis." AIDS Care, 16(6), 700-723.

[10] Albarracin, D., \& others. (2005). "A Test of Major Assumptions about Behavior Change: A Comprehensive Look at the Effects of Passive and Active HIV-Prevention Interventions since the Beginning of the Epidemic.”Psychological Bulletin, $131(6), 856-897$.

[11] Downs, D. S., \& Hausenblas, H. A. (2005) . "Elicitation Studies and the Theory of Planned Behavior: A Systematic Review of Exercise Beliefs." Psychology of Sport and Exercise, 6, 1-31.

[12] Durantini, M. R., \& others. (2006). "Conceptualizing the Influence of Social Agents of Change: A Meta-Analysis of HIV Prevention Interventions for Different Groups.” Psychological Bulletin, 132, 212-248.

[13] Hardeman, W., \& others. (2002). "Application of the Theory of Planned Behavior in Behavior Change Interventions: A Systematic Review." Psychology and Health, 17(2), 123-158.

[14] Sheeran, P., \& Taylor, S. (1999). "Predicting Intentions to Use Condoms: A Meta-Analysis and Comparison of the Theories of Reasoned Action and Planned Behavior.” Journal of Applied Social Psychology, 29, 1624-1675.

[15] Webb, T. L., \& Sheeran, P.(2006). "Does Changing Behavioral Intentions Engender Behavior Change? A Meta-Analysis of the Experimental Evidence.” Psychological Bulletin, 132, 249-268.

[16] Jemmott, J. B., Jemmott, L. S., \& Fong, G. T. (1992). "Reductions in HIV Risk-Associated Sexual Behaviors among Black Male Adolescents: Effects of an AIDS Prevention Intervention.” American Journal of Public Health, 82(3), 372-377.

[17] Kamb, M., \& others. (1988). "Efficacy of Risk-Reduction Counseling to Prevent Human Immunodeficiency Virus And Sexually Transmitted Diseases." Journal of the American Medical Association, 280, 1161-1167.

[18] Rhodes F., \& others. (2007). "Using Theory to Understand How Interventions Work: Project RESPECT, Condom Use and the Integrative Model." AIDS and Behavior, 11(3), 393-407.

[19] Ajzen, I. (1991). "The Theory of Planned Behavior." Organizational Behavior and Human Decision Processes, 50, $179-211$.

[20] Ajzen, I., \& Driver, B. L. (1991). "Prediction of Leisure Participation from Behavioral, Normative, and Control Beliefs: An Application of the Theory of Planned Behavior." Leisure Sciences, 13, 185-204.

[21] Ajzen, I., \& Madden, T. J. (1986). "Prediction of Goal-Directed Behavior: Attitudes, Intentions, and Perceived Behavioral Control." Journal of Experimental Social Psychology, 22, 453-474.

[22] Madden, T. J., Ellen, P. S., \& Ajzen, I. (1992). "A Comparison of the Theory of Planned Behavior and the Theory of Reasoned Action.” Personality and Social Psychology Bulletin, 18, 3-9.

[23] Yzer, M.(2007). Does Perceived Control Moderate Attitudinal and Normative Effects on Intention? A Review of Conceptualand Methodological Issues." Prediction and Changeof Health Behavior: Applying the Reasoned Action Approach. Hillsdale, N.J.: Erlbaum.

[24] Ajzen, I. (2002). "Perceived Behavioral Control, Self-Efficacy, Locus of Control, and the Theory of Planned Behavior.”Journal of Applied Social Psychology, 32, 1-20.

[25] Ajzen, I., \& Fishbein, M. (1980). "Understanding Attitudes and Predicting Social Behavior.” Englewood Cliffs, N.J.: Prentice Hall.

[26] Triandis, H. C. (1980). "Values, Attitudes, and Interpersonal Behavior." In H. E. Howe \& M. Page (Eds.), Nebraska Symposium on Motivation, 1979. Lincoln: University of Nebraska Press.

[27] Becker, M. H. (1974). "The Health Belief Model and Personal Health Behavior.” Health Education Monographs, $2,324-473$.

[28] Fishbein, M. (2007). “A Reasoned Action Approach: Some Issues, Questions, and Clarifications.” In I. Ajzen, D. Albarracin, \& R. Hornik (Eds.), Prediction and Change of Health Behavior: Applying the Reasoned Action Approach. Hillsdale, N.J.: Erlbaum.

[29] French, D. P., \& others. (2005). "The Importance of Affective Beliefs and Attitudes in the Theory of Planned Behavior: Predicting Intention to Increase Physical Activity." Journal of Applied Social Psychology, 35(9), 1824-1848.

[30] Bagozzi, R. P., \& Lee, K. H. (2002). "Multiple Routes for Social Influence: The Role of Compliance, Internalization and Social Identity." Social Psychology Quarterly, 65(3), 226-247.

[31] Triandis, H. C., \& others. (1988). "Individualism and Collectivism: Cross-Cultural Perspectives on Self-In Group Relationships.”Journal of Personality and Social Psychology, 54(2), 323-338.

[32] Bandura, A. (2006). "Toward a Psychology of Human Agency." Perspectives on Psychological Science, 1(2), 164-180.

[33] Ajzen, I. (2002). "Perceived Behavioral Control, Self-Efficacy, Locus of Control, and the Theory of Planned Behavior."Journal of Applied Social Psychology, 32, 1-20.

[34] von Haeften, I., \& Kenski, K. (2001). “Multi-Partnered Heterosexual's Condom Use for Vaginal Sex With Their Main Partner as a Function of Attitude, Subjective Norm, Partner Norm, Perceived Behavioral Control, and Weighted Control Beliefs.” Psychology, Health \& Medicine, 6(2), 165-178.

[35] von Haeften, I., Fishbein, M., Kasprzyk, D., \& Montaño, D. (2001). “Analyzing Data to Obtain Information to Design Targeted Interventions." Psychology, Health \& Medicine, 6(2), 151-164. 